\title{
Amyloid, tau, and astrocyte pathology in autosomal-dominant Alzheimer's disease variants: ABPParc and PSEN1DE9
}

\author{
Laetitia Lemoine $^{1} \cdot$ Per-Göran Gillberg ${ }^{1} \cdot$ Nenad Bogdanovic $\mathbb{D}^{1,2} \cdot$ Inger Nennesmo ${ }^{3} \cdot$ Laure Saint-Aubert ${ }^{1,4,5}$. \\ Matti Viitanen ${ }^{1,2,6} \cdot$ Caroline Graff $^{7,8} \cdot$ Martin Ingelsson $^{9} \cdot$ Agneta Nordberg $^{1} \mathbb{D}^{1,2}$
}

Received: 29 February 2020 / Revised: 4 June 2020 / Accepted: 8 June 2020 / Published online: 25 June 2020

(c) The Author(s) 2020. This article is published with open access

\begin{abstract}
Autosomal-dominant Alzheimer's disease (ADAD) may be associated with atypical amyloid beta deposits in the brain. In vivo amyloid imaging using ${ }^{11} \mathrm{C}$-Pittsburgh compound $\mathrm{B}(\mathrm{PiB})$ tracer has shown differences in binding between brains from $\mathrm{ADAD}$ and sporadic Alzheimer's disease (SAD) patients. To gain further insight into the various pathological characteristics of these genetic variants, we performed large frozen hemisphere autoradiography and brain homogenate binding assays with ${ }^{3} \mathrm{H}-\mathrm{PiB},{ }^{3} \mathrm{H}-\mathrm{MK} 6240-{ }^{3} \mathrm{H}-\mathrm{THK} 5117$, and ${ }^{3} \mathrm{H}$-deprenyl for detection of amyloid fibrils, tau depositions, and activated astrocytes, respectively, in two ABPParc mutation carriers, one PSEN1 $E E 9$ mutation carrier, and three sAD cases. The results were compared with Abeta 40, Abeta 42, AT8, and GFAP immunostaining, respectively, as well as with Congo red and Bielschowsky. PiB showed a very low binding in ABPParc. A high binding was observed in PSEN1 $E$ E9 and in SAD tissues but with different binding patterns. Comparable ${ }^{3} \mathrm{H}$-THK5117 and ${ }^{3} \mathrm{H}$-deprenyl brain homogenate binding was observed for ABPParc, PSEN1 $E$ E9, and sAD, respectively. Some differences were observed between ${ }^{3} \mathrm{H}-\mathrm{MK} 6240$ and ${ }^{3} \mathrm{H}$ THK5117 in ADAD. A positive correlation between ${ }^{3} \mathrm{H}$-deprenyl and ${ }^{3} \mathrm{H}$-THK5117 binding was observed in A PPParc, while no such correlation was found in PSENI $E$ E and sAD. Our study demonstrates differences in the properties of the amyloid plaques between two genetic variants of $\mathrm{AD}$ and SAD. Despite the lack of measurable amyloid fibrils by PiB in the A $\beta$ PParc cases, high regional tau and astrocyte binding was observed. The lack of correlation between ${ }^{3} \mathrm{H}-\mathrm{deprenyl}$ and ${ }^{3} \mathrm{H}-$ THK5117 binding in PSENIAE9 and SAD in contrast of the positive correlation observed in the ABPParc cases suggest differences in the pathological cascade between variants of $\mathrm{AD}$ that warrant further exploration in vivo.
\end{abstract}

Supplementary information The online version of this article (https:// doi.org/10.1038/s41380-020-0817-2) contains supplementary material, which is available to authorized users.

Agneta Nordberg

Agneta.K.Nordberg@ki.se

1 Division of Clinical Geriatrics, Department of Neurobiology, Care Sciences and Society, Center for Alzheimer Research, Karolinska Institutet, Stockholm, Sweden

2 Theme Aging, The Aging Brain, Karolinska University Hospital, Stockholm, Sweden

3 Department of Pathology, Karolinska University Hospital, Stockholm, Sweden

4 ToNIC, Toulouse NeuroImaging Center, University of Toulouse, Inserm, UPS, Toulouse, France

\section{Introduction}

In a small percentage of patients, Alzheimer's disease $(\mathrm{AD})$ is characterized by an early onset due to a mutation in one of three identified genes: amyloid-beta precursor protein $(A \beta P P)$, Presenilin 1 (PSEN1), and Presenilin 2 (PSEN2). Mutation-specific features have been described,

5 Nuclear Medicine Department, University Hospital of Toulouse, Toulouse, France

6 Department of Geriatrics, Turku City Hospital, Turku University, Turku, Finland

7 Division of Neurogeriatrics, Department of Neurobiology, Care Sciences and Society, Center for Alzheimer Research, Karolinska Institutet, Stockholm, Sweden

8 Theme Aging, Unit for Hereditary Dementia, Karolinska University Hospital, Stockholm, Sweden

9 Department of Public Health and Caring Sciences, Geriatrics, Uppsala University, Uppsala, Sweden 
both in vitro and in vivo, showing a faster progression of the disease in Autosomal-dominant Alzheimer's disease (ADAD) variants in comparison to the sporadic form of Alzheimer's disease (sAD) [1]. However, not all identified mutations will result in the clinical phenotype of AD [2].

In PSEN1DE9 brains, (due to an exon 9 deletion in PSEN1 (PSEN1DE9) identified in the FINN2 family [3]) accumulation of large plaques composed of amyloid beta 42 and amyloid beta 40 without a compact amyloid core so called 'cotton wool' plaques have been reported [4]. Significant difference was observed between PSEN1DE9 mutation and SAD with significantly higher Abeta 42/40 ratio in PSEN1DE9 [4]. PSEN1DE9 is distinct from the SAD phenotype and could also result for some cases, in a clinical phenotype that includes spastic paraparesis [3]. The A $\beta P$ Parc mutation (p. E693G) is pathologically characterized by the presence of ring-shaped amyloid plaques without amyloid core [5]. Those plaques are Congo red negative but amyloid beta 42-positive on the ring as observed using amyloid beta 1-42 antibodies [1, 6]. The clinical phenotype in A PParc is similar to that in patients with SAD but with an earlier onset of the disease (45-57 years) [3]. Previous in vitro studies have shown increased levels of oligomeric and protofibrillar forms of amyloid beta in A PPParc oligomeric preparations [7, 8]. Philipson et al., in 2012 compared both the amyloid plaques structure and the accumulations of $\mathrm{N}$ - and C-truncated $A \beta$ in A PPParc, PSEN1DE9 and $S A D$, and they could observe differences in length accumulation of $\mathrm{N}$ - and C-truncated $\mathrm{A} \beta 40$ and 42 between the two mutation and SAD in parenchymal plaques as well as in cerebral amyloid angyopathy [9]. The in vivo PET binding of ${ }^{11} \mathrm{C}$-Pittsburgh compound $\mathrm{B}(\mathrm{PiB})$ is low in both symptomatic and nonsymptomatic $A \beta P P$ arc carriers in comparison to patients with SAD while levels of amyloid beta 42 , total tau and P-tau in the cerebrospinal fluid and cerebral metabolism as measured by ${ }^{18} \mathrm{~F}$ fluorodeoxyglucose (FDG) PET are comparable with sAD $[6,10,11]$.

In the PSEN1DE9 mutation carriers, ${ }^{11} \mathrm{C}-\mathrm{PIB}$ PET has demonstrated increased amyloid plaque deposition in comparison to control and with a distinct pattern than SAD with a higher ${ }^{11} \mathrm{C}$-PIB binding in the putamen in comparison to sAD patients [12]. ${ }^{18}$ F-FDG hypometabolism and pathological levels of CSF biomarkers were comparable to those observed in SAD patients [12].

In this study, our aim was to further characterize the neuropathological features of two ABPParc and one PSEN1DE9 mutation carrier using autoradiography with PET tracers as well as immunohistochemistry, in order to assess the extent and regional distribution of plaques, tangles, and activated astrocytes. An ante-mortem/postmortem binding comparison was performed for one A $\beta P$ Parc case.

\section{Material and methods}

\section{Autopsy material}

Large frozen whole left hemisphere sections were obtained from two A PPParc (A $\beta P P$ arc1, provided by the Brain Bank at Karolinska Institutet; $A \beta P P a r c 2$, provided by the Uppsala University brain bank), one PSEN1DE9 (provided by the Department of Pathology, University of Helsinki, Helsinki, Finland) and from the right hemisphere for three sAD brains (provided by the Neuropathology of Dementia Laboratory, Indiana University School of Medicine, Indianapolis, IN, USA). Direct comparison between the cases should be taken with caution due to the fact that large frozen hemisphere sections are rare material and the sections were not from the exact same coronal anatomical level. For the two A $\beta P P a r c$, and the three SAD pieces of frontal, temporal, and entorhinal cortices, as well as hippocampus and caudate nucleus were dissected and used for binding assay studies. For the PSEN1DE9, frontal, temporal cortices, and caudate were available. Frozen homogenates of frontal cortex, temporal cortex, hippocampus, and caudate nucleus from two nondemented controls (obtained from the Netherlands Brain Bank) were used for binding assays. The demographic data are presented in Table 1. Clinical description of the patients with A PPAarc and PSEN1 $E$ E9 mutations is available on Supplementary data 1 .

\section{Chemicals}

${ }^{3}$ H-THK5 117 and unlabeled THK5117 were synthesized by Novandi chemistry AB (Södertälje, Sweden; specific

Table 1 Table representing the clinical information.

\begin{tabular}{|c|c|c|c|c|c|c|}
\hline & Sex & $\begin{array}{l}\text { Age of } \\
\text { onset } \\
\text { (years) }\end{array}$ & $\begin{array}{l}\text { Age at } \\
\text { death } \\
\text { (years) }\end{array}$ & Braak stage & APOE & PMI (h) \\
\hline$A \beta P P a r c 1$ & $\mathrm{~F}$ & 53 & 66 & VI & $3 / 3$ & $>30$ \\
\hline$A \beta P P a r c 2$ & M & 61 & 64 & VI & $3 / 3$ & 12 \\
\hline PSEN1 $1 \triangle E 9$ & $\mathrm{~F}$ & 51 & 66 & N/A & $3 / 3$ & 5 \\
\hline $\mathrm{AD} 1$ & $\mathrm{~F}$ & & 59 & VI & $3 / 3$ & 4 \\
\hline $\mathrm{AD} 2$ & $\mathrm{~F}$ & & 73 & $\mathrm{~V}$ & $3 / 3$ & 1.5 \\
\hline AD3 & $\mathrm{F}$ & & 59 & $\mathrm{~V}$ & $3 / 4$ & 10 \\
\hline Control 1 & M & & 62 & I & $3 / 3$ & 7 \\
\hline Control 2 & $\mathrm{~F}$ & & 71 & I & $3 / 2$ & 7 \\
\hline Control 3 & M & & 79 & II & $3 / 3$ & 9 \\
\hline
\end{tabular}

Demographic information for patients with autosomal-dominant Alzheimer's disease, patients with sporadic Alzheimer's disease and normal controls.

$A D$ Alzheimer's disease, APOE apolipoprotein E, ABPParc Arctic amyloid- $\beta$ protein precursor mutation, $F$ female, $M$ male, $N / A$ not applicable, $P M I$ postmortem interval, PSEN1 $E$ E9 PS1 exon 9 deletion. 
activity $(\mathrm{SA})=75 \mathrm{Ci} / \mathrm{mmol}) .{ }^{3} \mathrm{H}-\mathrm{MK} 6240$ and unlabeled MK6240 were synthesized by Merck \& Co; SA: $44 \mathrm{Ci} /$ mmol. ${ }^{3} \mathrm{H}-\mathrm{PIB}$ was custom synthesized by Novandi (Södertälje, Sweden; SA = $73 \mathrm{Ci} / \mathrm{mmol}$ ). ${ }^{3} \mathrm{H}$-L-deprenyl was custom synthesized by Quotient Bioresearch (Cardiff, UK; $\mathrm{SA}=85 \mathrm{Ci} / \mathrm{mmol}$ ). Unlabeled (R)-(-)-deprenyl was purchased from Tocris Bioscience and BTA-1 was purchased from Sigma-Aldrich.

\section{Autoradiography}

Autoradiography from all cases was carried out at room temperature (RT) on frozen coronal sections $(100 \mu \mathrm{m}$ thick using a Cryomacrotome Leica CM3600XP, Leica Biosystems, USA) after allowing them to dry. For ${ }^{3} \mathrm{H}-\mathrm{PIB}$, the sections were preincubated for $15 \mathrm{~min}$ with Phosphate Buffer Saline (PBS) $+1 \%$ BSA, then incubated for $45 \mathrm{~min}$ with ${ }^{3} \mathrm{H}-\mathrm{PIB}(1 \mathrm{nM})$ in $\mathrm{PBS}+0.1 \%$ BSA. Nonspecific (NSP) binding was determined with $1 \mu \mathrm{M}$ BTA-1. For ${ }^{3} \mathrm{H}-$ THK5117 and ${ }^{3} \mathrm{H}-\mathrm{MK} 6240$, the sections were preincubated 15 min with PBS $+0.1 \%$ BSA, then incubated for $1 \mathrm{~h}$ with ${ }^{3} \mathrm{H}$-THK5117 $(3 \mathrm{nM})$ or ${ }^{3} \mathrm{H}-\mathrm{MK} 6240(1 \mathrm{nM})$ with the same buffer. NSP was determined with $1 \mu \mathrm{M}$ unlabeled THK5117 or MK6240, respectively. Finally, for ${ }^{3} \mathrm{H}$-deprenyl autoradiography the sections were incubated with ${ }^{3} \mathrm{H}$-deprenyl $(10 \mathrm{nM})$ for $1 \mathrm{~h}$ in $\mathrm{Na}-\mathrm{K}$ phosphate buffer. NSP was determined with $1 \mu \mathrm{M}$ of unlabeled deprenyl.

For all the radioligands, the binding reaction was terminated by washing $3 \times 5 \mathrm{~min}$ with cold binding buffer $\left(4^{\circ}\right.$ C) followed by one dip in cold distilled water $\left(4^{\circ} \mathrm{C}\right)$. The sections were then dried and apposed on photostimulable phosphor-plates for 4 days for ${ }^{3} \mathrm{H}$-deprenyl and ${ }^{3} \mathrm{H}$ THK5117 and 7 days for ${ }^{3} \mathrm{H}-\mathrm{PIB}$ and ${ }^{3} \mathrm{H}-\mathrm{MK} 6240$. The photostimulable phosphor-plates were then read using a BAS-2500 imager and the results were analyzed using multigauge software to draw the regions of interest manually.

\section{Immunohistochemistry for neuropathological evaluation}

Immunohistochemistry for neuropathological evaluation was performed on small paraffin-embedded sections from right brain hemisphere obtained from the same cases mentioned above (ABPParc1, ABPParc2, and PSEN1DE9) (For $A \beta P P a r c 16 \mu \mathrm{m}$ thick sections on no coated slides were used; for $A \beta P P a r c 27 \mu \mathrm{m}$ thick sections on coated slides were used and for PSENIDE9 $7 \mu \mathrm{m}$ thick sections on superfrost slides were used).

A routine deparaffinization protocol was used. AT8 (Phospho-Tau, Ser202, Thr205) monoclonal antibody from Thermofisher, amyloid beta 1-42 (antiamyloid $\beta 42$ antibody, clone G2-11 from Merck Millipore), and amyloid beta 1-40 (antiamyloid $\beta 40$ antibody, clone G2-10 from Merck milipore) antibodies were used as follows: AT8 dilution 1:2500 stained in Roche Ventana immunostainer; amyloid beta 1-42 dilution 1:750 and amyloid beta 1-40 dilution 1:500 stained in Roche Ventana immunostainer but with $10 \mathrm{~min}$ in formic acid first after deparaffination.

\section{In vitro brain regional binding studies}

Regional binding studies were carried out on fresh frozen tissues from frontal, temporal, and entorhinal cortices, caudate nucleus and hippocampus using ${ }^{3} \mathrm{H}-\mathrm{PIB},{ }^{3} \mathrm{H}-$ deprenyl, and ${ }^{3} \mathrm{H}-\mathrm{THK} 5117$. Each compound was incubated with the brain homogenates and filtered after a tracerspecific incubation time, as follow: ${ }^{3} \mathrm{H}-\mathrm{PIB}(1 \mathrm{nM})$ was incubated in PBS for $2 \mathrm{~h}$ at RT with $0.1 \mathrm{mg} / \mathrm{ml}$ of tissue. NSP was determined using $1 \mu \mathrm{M}$ of BTA-1. ${ }^{3} \mathrm{H}$-deprenyl $(10 \mathrm{nM})$ was incubated for $1 \mathrm{~h}$ at $37^{\circ} \mathrm{C}$ with $0.2 \mathrm{mg} / \mathrm{ml}$ of tissue using $\mathrm{Na}-\mathrm{K}$ phosphate buffer. NSP was determined using $1 \mu \mathrm{M}$ unlabeled deprenyl. ${ }^{3} \mathrm{H}$-THK5117 $(3 \mathrm{nM})$ was incubated for $2 \mathrm{~h}$ at RT with $0.2 \mathrm{mg} / \mathrm{ml}$ of tissue using PBS $+0.1 \%$ BSA. NSP was determined using $1 \mu \mathrm{M}$ unlabeled THK5117.

All experiments were terminated by filtering through glass fiber filter paper presoaked with polyethylenimine $0.3 \%$, rinsing three times with cold binding buffer and then counting on a Beckman scintillation counter. Each experiment was performed at least in triplicate and analyzed using graph pad prism software.

\section{$A \beta P P a r c$ in vivo imaging}

Two years before death, the A $\beta P$ Parcl patient underwent a structural T1 MPRAGE MRI on a 3T (Siemens Trio) scanner at the Karolinska University Hospital, Huddinge (Sweden), and PET examinations with ${ }^{11} \mathrm{C}$-deprenyl, ${ }^{11} \mathrm{C}$ PIB, and ${ }^{18}$ F-FDG at the Uppsala PET Centre, Uppsala University (Sweden), on an ECAT EXACT HR + (Siemens/CTI) PET/CT scanner. Productions of the tracers and image acquisitions have been previously described [6].

\section{Results}

\section{Autoradiography and immunostaining comparison}

The regional binding of ${ }^{3} \mathrm{H}$-PIB on large frozen brain sections of the two ABPParc mutation carriers, the PSENIDE9 mutation carrier and one SAD case is presented in Fig. $1 .{ }^{3} \mathrm{H}-$ PIB binding was very low in the whole brain hemisphere sections of the two A PPParc brains in comparison to the $\mathrm{SAD}$ brain. In contrast, the binding in the PSENIDE9 brain was higher and comparable to that in the sAD brain, but with a 


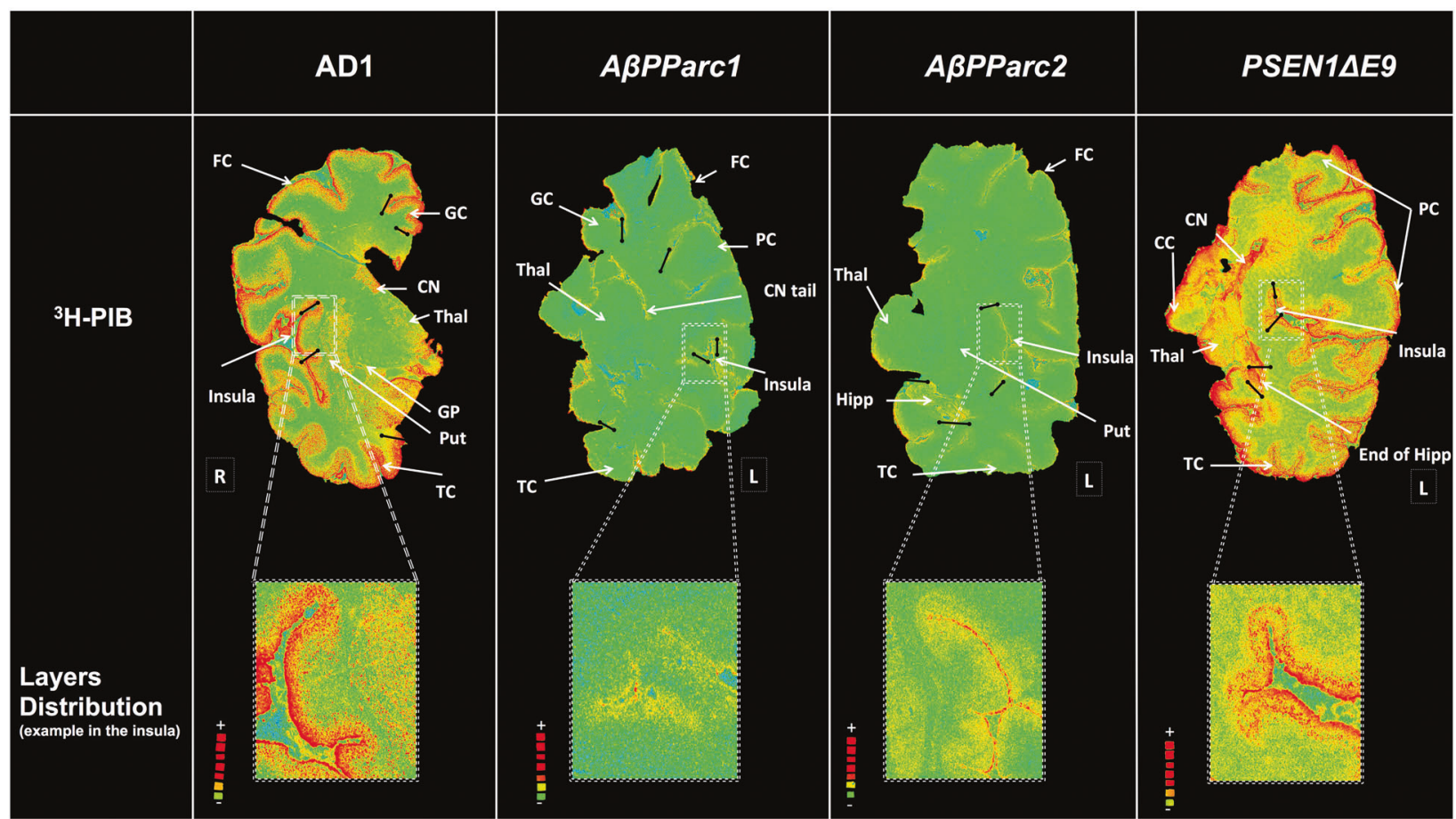

Fig. 1 Representation of total binding autoradiography on large frozen sections with ${ }^{3} \mathrm{H}$-Pittsburg compound $\mathrm{B}$. Autoradiography on large frozen sections from one Alzheimer's disease brain (AD1), two ABPParc brains and one PSEN1DE9 deletion brain. The top panel shows ${ }^{3} \mathrm{H}$-Pittsburgh compound B (PIB) autoradiography (standard: $+=4700 \mathrm{fmol} / \mathrm{mg},-=50 \mathrm{fmol} / \mathrm{mg}$ ) and the bottom panel shows

more uneven distribution ('cloudy' pattern) (see enlargement in Fig. 1). Some ${ }^{3}$ H-PIB binding could also observed in the white matter of the PSENIDE9 brain. A comparison of the immunostaining using amyloid $\beta 40$, amyloid $\beta$ 42, and Bielschowsky staining is presented in Fig. 2. The Bielschowsky stain bound to senile plaques and neurofibrillary tangles more intensely in the two A $\beta P$ Parc brains than in the PSENIDE9 brain. The amyloid $\beta 40$ and 42 staining was also intense in all layers for the two A PPAarc brains, with more spreading in the upper layers. In the PSENIDE9 brain, amyloid $\beta 42$ staining was more intense than amyloid $\beta$ 40 staining; amyloid staining was especially intense in layer 1 (corresponding to subpial amyloid accumulation). Amyloid beta 42 antibodies resulted in more compact, filled-in 'cotton wool' plaques in the PSENIDE9 brain than the ring-shaped plaques in the two ABPParc brains (Fig. 2). In the ABPParc brains, the specific ring shape of the plaques was observed predominantly with amyloid $\beta 42$ staining, which was located on the outer rims of the plaques; amyloid $\beta 40$ binding was homogeneously distributed throughout the plaque formations. The prominent difference between the 'cotton wool' plaques in the PSENIDE9 brain and the ring-shaped plaques in the ABPParc brains was clearly illustrated by Congo red (see Fig. 2). enlargements of the insula region to illustrate distribution in the layers. All images were put on the same threshold $(47,545)$ from the raw images (16 bits: 0-65,535 (color scale)) for comparison. CN caudate nucleus, CC corpus callosum, FC frontal cortex, GC gyrus cingulate, GP globus pallidus, Hipp hippocampus, Put putamen, PC parietal cortex, TC temporal cortex, Thal thalamus.

The regional binding pattern of ${ }^{3} \mathrm{H}$-deprenyl, ${ }^{3} \mathrm{H}-$ THK5117, and ${ }^{3} \mathrm{H}-\mathrm{MK} 6240$ are presented in the Fig. 3. ${ }^{3} \mathrm{H}$-deprenyl autoradiography showed the most intensity of binding compared with the two-tau tracers using the same color scale. An interesting difference between the two genetic variants and SAD was the binding of ${ }^{3} \mathrm{H}$ deprenyl in the white matter of the PSENIDE9 as confirmed by intensive immunostaining using the glial fibrillary acidic protein (GFAP) stain (Fig. 2). While comparing the two-tau tracers ${ }^{3} \mathrm{H}$-THK5117 and ${ }^{3} \mathrm{H}$ MK6240, lower general binding intensity was observed for ${ }^{3} \mathrm{H}$-MK6240 due to different SA ( $44 \mathrm{Ci} / \mathrm{mmol}$ for ${ }^{3} \mathrm{H}$ MK6240 and $85 \mathrm{Ci} / \mathrm{mmol}$ for ${ }^{3} \mathrm{H}$-THK5117) as well as incubation concentration $\left(1 \mathrm{nM}\right.$ for ${ }^{3} \mathrm{H}-\mathrm{MK} 6240$ and $4 \mathrm{nM}$ for ${ }^{3} \mathrm{H}$-THK5117). Regional distribution binding was similar for the two-tau tracers in the sAD. For A PPParcl, ${ }^{3} \mathrm{H}-\mathrm{MK} 6240$ binding is higher than the one of ${ }^{3} \mathrm{H}$ THK5117. For ABPParc2 and PSENIDE9 differences were observed between the two-tau tracers. Indeed, in PSENIDE9 lower ${ }^{3} \mathrm{H}-\mathrm{MK} 6240$ binding was observed in temporal area in comparison to other cases. ${ }^{3} \mathrm{H}$-THK5117 binding was more extensive throughout the cortical ribbon in the $A \beta P P a r c 2$ brain than in the $A \beta P P a r c 1$ brain, again confirmed by GFAP and AT8 immunostaining (Fig. 2). 


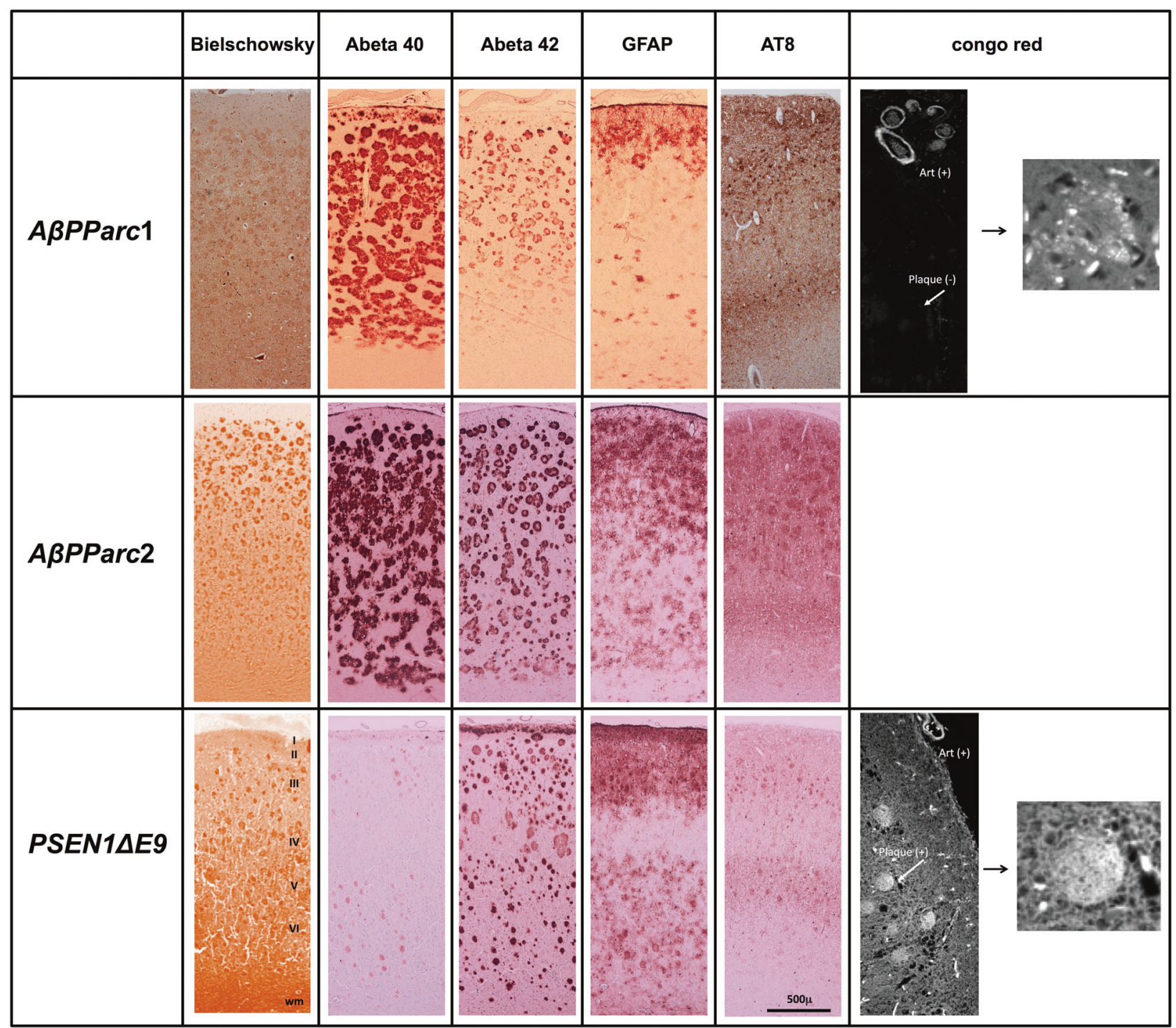

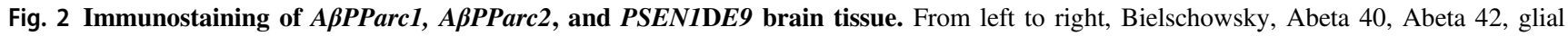
fibrillary acidic protein (GFAP), and AT8 stains and Congo red.

GFAP and AT8 immunostaining also showed differential bilayer distribution in the superficial and deep pyramidal layers of the three ADAD (data not shown). In the PSENIDE9 brain, AT8 staining was similar to that in the sAD brain but was less intense than that in the two $A \beta P P a r c$ brains. In the A PPParc 2 brain, GFAP and AT8 immunostaining was more intense throughout all the layers, including the superficial layer, than in the $A \beta P$ Parc 1 brain. In both the A PPParc brains, AT8 staining followed the distribution of the amyloid plaques, depicting binding in the neuritic plaques. GFAP staining was more intense in the PSENIDE9 brain than in the two $A \beta P P a r c$ brains, with intense binding in the upper layers (including the molecular layer with subpical positivity) and in the white matter.

\section{Quantitative assessment of the regional binding distribution of ${ }^{3} \mathrm{H}-\mathrm{PIB},{ }^{3} \mathrm{H}-\mathrm{THK} 5117$, and ${ }^{3} \mathrm{H}$-deprenyl}

Regional binding of the three PET tracers was quantitatively assessed using brain homogenates in binding assays; results are shown in Fig. 4. Low ${ }^{3}$ H-PIB binding was observed in the two ABPParc brains compared with intermediate binding in the PSENIDE9 brain and high binding in SAD (Fig. 4a). The binding in the caudate was in general similar to the cortical binding. In the AD cases the caudate showed an intermediate binding while both higher and lower cortical binding were observed, probably due to larger intracases variability. Higher ${ }^{3} \mathrm{H}$-THK5117 binding was detected in the frontal and temporal cortices in the SAD brains compared with the ABPParc and PSENIDE9 brains 


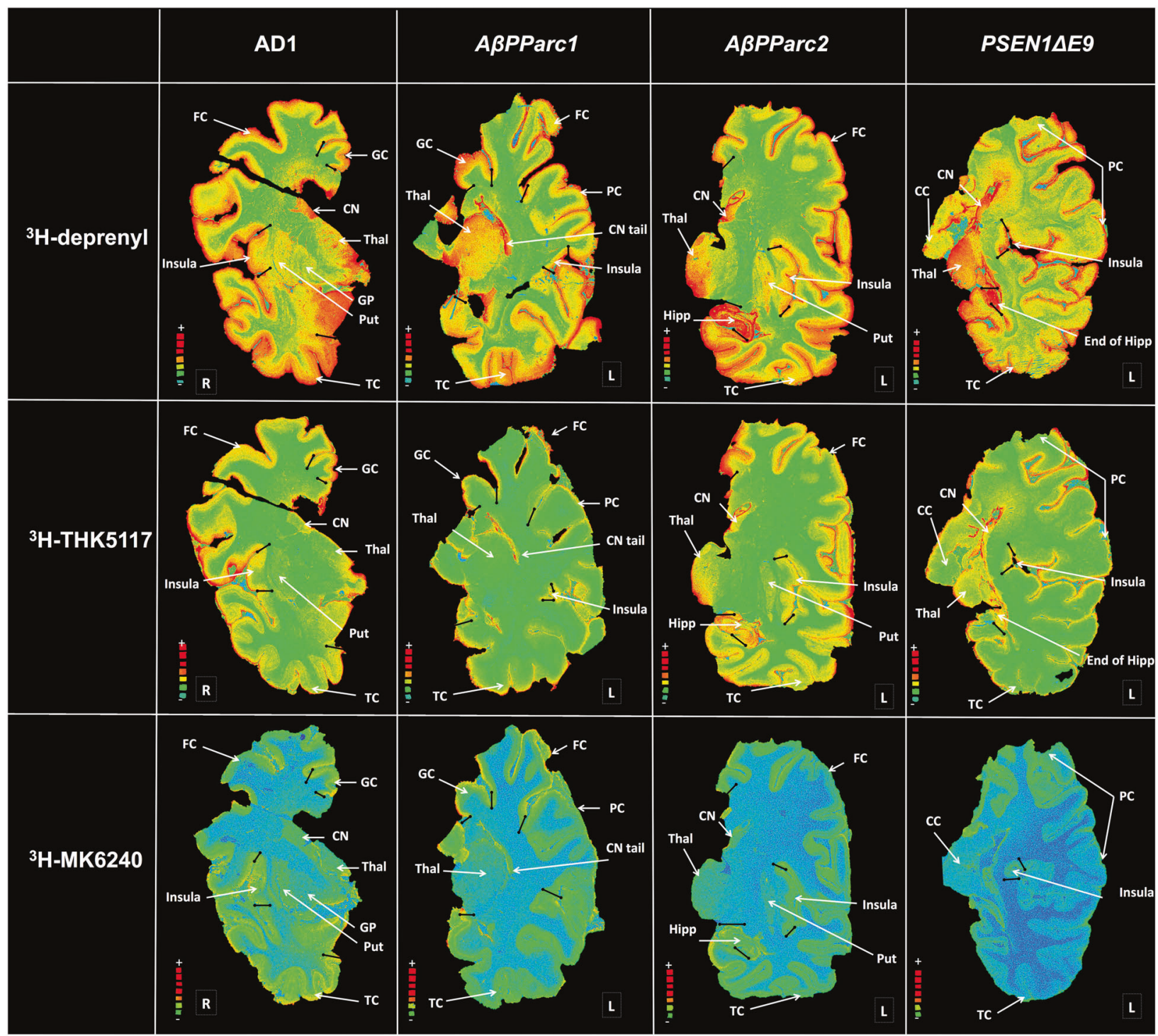

Fig. 3 Representation of total binding autoradiography on large frozen sections with ${ }^{3} \mathrm{H}$-deprenyl, ${ }^{3} \mathrm{H}$-THK5117, and ${ }^{3} \mathrm{H}$-MK6240. Autoradiography on large frozen sections from one Alzheimer's disease (AD) brain, two ABPParc brains and one PSEN1DE9 deletion brain. The top panel shows ${ }^{3} \mathrm{H}$-deprenyl autoradiography (Standard: + $=4100 \mathrm{fmol} / \mathrm{mg},-=50 \mathrm{fmol} / \mathrm{mg}$ ), middle panel shows ${ }^{3} \mathrm{H}-\mathrm{THK} 5117$ autoradiography (standard: $+=4500 \mathrm{fmol} / \mathrm{mg},-=30 \mathrm{fmol} / \mathrm{mg}$ ) and the bottom panel shows ${ }^{3} \mathrm{H}-\mathrm{MK} 6240$ autoradiography (standard: $+=$

(Fig. 4b). The highest ${ }^{3} \mathrm{H}$-THK5117 mean binding was observed in the hippocampus of the ABPParc 1 brain, in the entorhinal cortex of the $A \beta P P a r c 2$ brain, and in the caudate nucleus of the PSENIDE9 brain. Binding in the frontal and temporal cortices was similar for the two ABPParc and slightly higher in the PSENIDE9 brains. The binding in caudate is higher than in the cortex in all mutation brains except in $\mathrm{SAD}$ and control.

${ }^{3} \mathrm{H}$-deprenyl binding was similar in the frontal cortex and in the caudate nucleus for both sporadic and mutation cases. Greater ${ }^{3} \mathrm{H}$-deprenyl binding was observed in the
$6500 \mathrm{fmol} / \mathrm{mg}, \quad-=70 \mathrm{fmol} / \mathrm{mg}$ ). All images from deprenyl and THK5117 tracers were put on the same threshold $(50,372)$ from the raw images ( 16 bits :0-65,535 (color scale)) for comparison. For MK6240 threshold were putted at 46,517 to allow comparison with other tracers. CN caudate nucleus, CC corpus callosum, FC frontal cortex, GC gyrus cingulate, GP globus pallidus, Hipp hippocampus, Put putamen, PC Parietal cortex, TC temporal cortex, Thal thalamus.

hippocampus of the ABPParcl case and the entorhinal cortex of $A \beta P P$ arc 2 compared with sAD cases (Fig. 4c). Caudate binding is higher than the cortex binding in all $\mathrm{AD}$ brains while lower than the entorhinal cortex and hippocampus in the two ABPParc.

\section{Relationship between ${ }^{3} \mathrm{H}$-deprenyl and ${ }^{3} \mathrm{H}$-THK5117 regional binding}

A significant positive correlation between ${ }^{3} \mathrm{H}$-deprenyl and ${ }^{3} \mathrm{H}$-THK5117 binding was observed for the two ABPParc in 

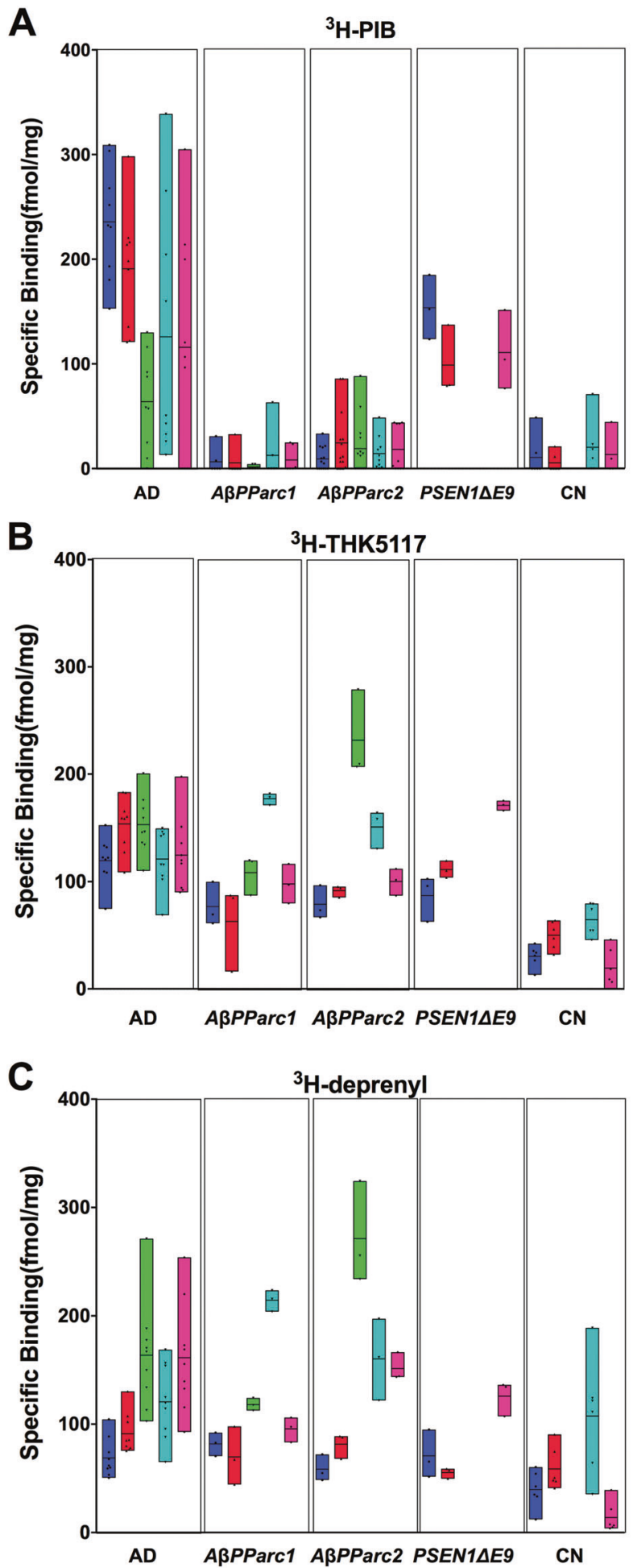

$\square$ Frontal cortex $\square$ temporal cortex $\square$ entorhinal cortex $\square$ hippocampus $\square$ caudate

Fig. 4 Regional-specific binding distribution assays. Regionalspecific binding distribution assays using single concentrations of (a) ${ }^{3} \mathrm{H}$-Pittsburgh compound B (PIB); (b) ${ }^{3} \mathrm{H}$-THK5117 and (c) ${ }^{3} \mathrm{H}$-deprenyl in two ABPParc brains, one PSEN1DE9 brain, three sporadic Alzheimer's disease (AD) brains and three normal control brains. Frontal cortex, entorhinal cortex, caudate nucleus, temporal cortex, and hippocampus were investigated depending on the availability of the tissue.

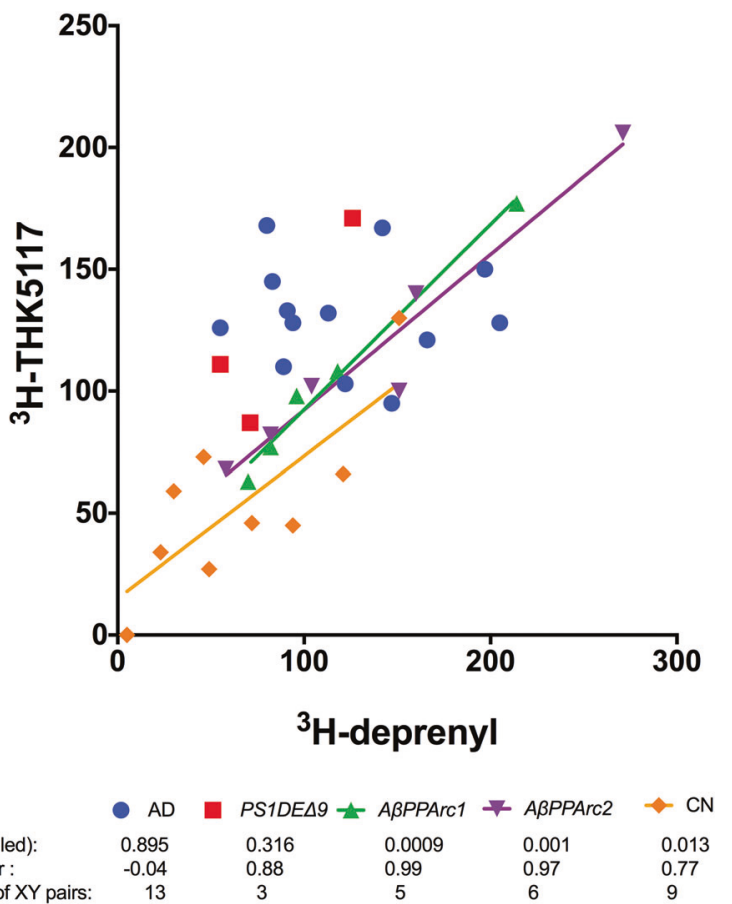

Fig. 5 Correlation between ${ }^{3} \mathrm{H}$-THK5117 and ${ }^{3} \mathrm{H}$-deprenyl binding. Comparison of deprenyl and THK5117 regional binding distributions in two ABPParc brains, one PSEN1DE9 brain, three Alzheimer's disease brains, and three normal control brains. Frontal cortex, temporal cortex, entorhinal cortex, caudate nucleus, and hippocampus tissue was used depending on availability. $n=$ number of samples investigated.

different brain regions, while no such significant correlations were observed for the SAD or PSEN1DE9 brains (Fig. 5). No significant correlations were seen between ${ }^{3} \mathrm{H}$ PIB and ${ }^{3} \mathrm{H}-\mathrm{THK} 5117$ in any group (Supplementary data 2a). Between ${ }^{3} \mathrm{H}$-PIB and ${ }^{3} \mathrm{H}$-Deprenyl significant negative correlation could be observe only in SAD (Supplementary data $2 b$ ).

\section{AßPParc1 brain multitracer PET scan}

Parametric images of PET acquisitions using ${ }^{11} \mathrm{C}-\mathrm{L}$ deprenyl, ${ }^{18} \mathrm{~F}-\mathrm{FDG}$, and ${ }^{11} \mathrm{C}$-PIB in the ABPParcl carrier performed 2 years prior to death are shown in Fig. 6. The ${ }^{11} \mathrm{C}$-PIB PET scan showed very low binding and considered to be amyloid negative according to used cutoff values [13]. The ${ }^{18}$ F-FDG PET scan showed cortical hypometabolism, predominantly in the temporo-parietal regions, and ${ }^{11} \mathrm{C}$-deprenyl showed high binding in the cortical regions and basal ganglia (Fig. 6) (see Supplementary data 3 for in vivo-in vitro correlation for ABPParc1). 


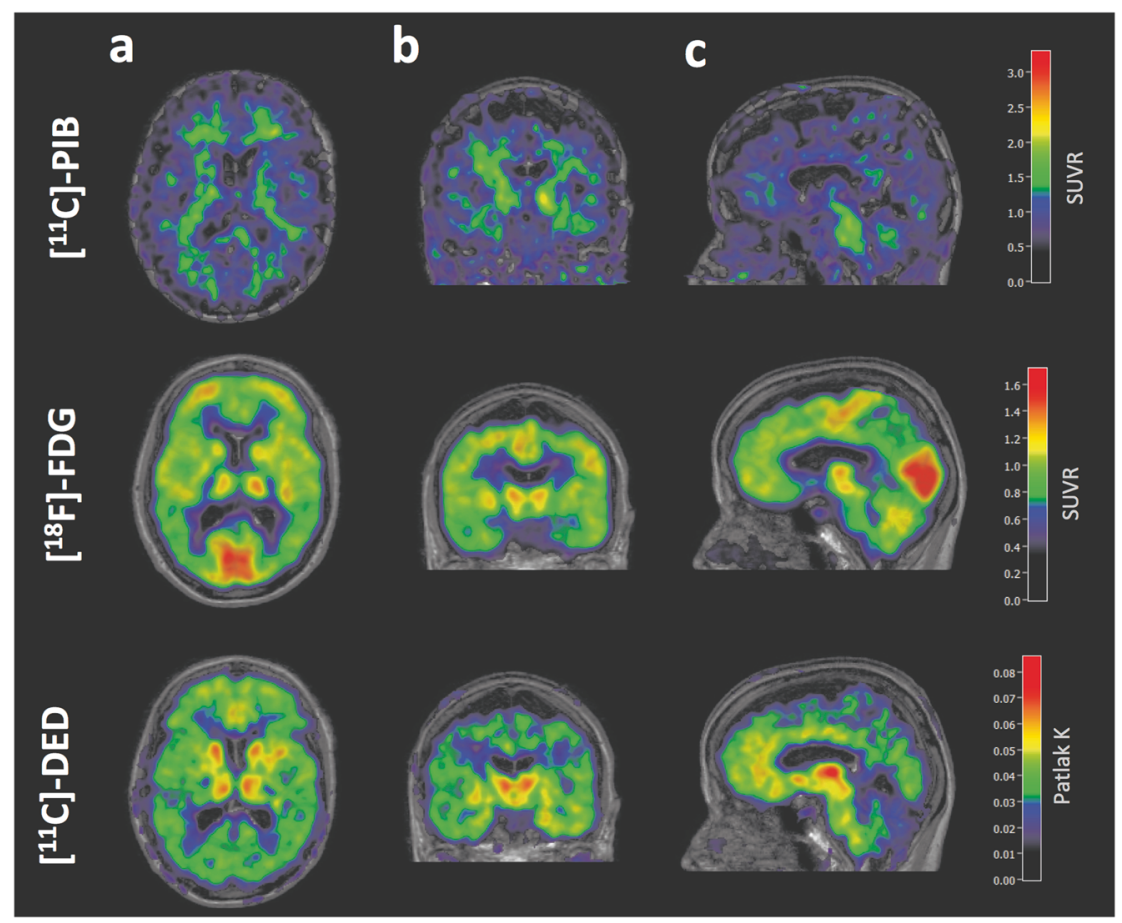

Fig. 6 Multitracer PET scans for ABPParc1 mutation carrier Multitracer PET scan for an ABPParc mutation carrier (ABPParc1) using ${ }^{11}$ C-Pittsburgh compound $B$ (PIB), ${ }^{18}$ Ffludeoxyglucose (FDG), and ${ }^{11} \mathrm{C}$-deprenyl tracers. $\left({ }^{11} \mathrm{C}\right.$-PIB and ${ }^{18}$ F-FDG late sum images (40-60 and 30-45 min, respectively) were created and co-registered onto the T1 MRI image. The whole pons was used as a reference for both tracers as it was found to be preserved

\section{Discussion}

The aim of the study was to compare the neuropathological features of the ABPParc and PSENIDE9 mutations with those of SAD using in vitro binding studies of autopsied brain tissue with PET ligands, in order to be able to understand the relationships between the different hallmarks of AD pathology.

Autoradiographies with ${ }^{3} \mathrm{H}-\mathrm{PIB}$ binding confirmed the in vivo data: the lack of ${ }^{3} \mathrm{H}$-PIB binding in the two A $\beta P P$ arc brains reflects the absence of fibrillar form (Congo positive) amyloid plaques in the two ABPParc brains. However, ${ }^{3} \mathrm{H}-$ PIB autoradiography showed relatively intense binding in the PSENIDE 9 brain, comparable to sAD brains. ${ }^{3} \mathrm{H}-\mathrm{PIB}$ binding in the PSENIDE9 brain was distributed mostly in the upper layers of the cortex, with specific binding also detected in the white matter. The PSENIDE9 brain has been shown to have rich amyloid angiopathy as observed with thioflavin-S [3] as well as ABPParc [1]. Interestingly, we confirmed these differences in the ${ }^{3} \mathrm{H}$-PIB binding pattern using amyloid $\beta 42$ and 40 antibody immunostaining. A striking difference between ABPParc and PSEN1DE9 was observed with the amyloid $\beta 40$ antibody; there was much less staining in the from pathology in both autosomal-dominant and sporadic Alzheimer's disease [14]. The ${ }^{11} \mathrm{C}$-deprenyl dynamic PET images were coregistered onto the T1 MRI image, and a modified reference Patlak model [15] was applied to the 20-60 min image using PMOD software, with the cerebellum as the modified reference region [16] to generate individual 3D parametric Patlak slope images (unit $=$ $\left.\min ^{-1}\right)$ ). a horizontal section; b coronal section; $\mathbf{c}$ sagittal section.

PSENIDE9 brain than in the two A PPParc brains. This major difference illustrates the different biological compositions of the amyloid plaques in ABPParc and PSENIDE9 mutations. These differences were confirmed with Congo red staining; there was a total Congo red negative core for the ABPParc brains and some positivity for the PSENIDE9 brain, but it was still more diffusely and evenly distributed (like cotton wool) in comparison to the SAD brains. In previous studies, Philipson et al. [9] have also demonstrated the differences between the biological composition of the amyloid plaques of ABPParc and PSEN1DE9 mutations. Moreover, Verkkoniemi et al., showed that both noncored, cored as well as diffuse plaques were found in the cerebral cortex of a patient with the FINN2 PSENIDE9 mutation [14].

The other characteristic pathological hallmarks of $\mathrm{AD}$, such as tau deposits and activated astrocytes, measured by ${ }^{3} \mathrm{H}$-THK5117/ ${ }^{3} \mathrm{H}-\mathrm{MK} 6240$ and ${ }^{3} \mathrm{H}$-deprenyl, respectively, showed more similarities across the ABPParc, PSENIDE9 and less similar with SAD brains. The most striking similarities is that both tau deposits and activated astrocytes binding are the highest in the limbic areas $>$ caudate $>$ cortical areas for the two ABPParc and PSENIDE9, when in the $\mathrm{SAD}$, these differences are not pronounced. 
For both the PSENIDE9 and the ABPParc mutations, similar laminar distributions throughout the cortical ribbon were observed for ${ }^{3} \mathrm{H}$-THK5117 and ${ }^{3} \mathrm{H}$-deprenyl. The similar results have already been described for SAD autoradiography using ${ }^{3} \mathrm{H}$-THK5117 and ${ }^{3} \mathrm{H}$-deprenyl [15]. This bilayer pattern was confirmed using GFAP and AT8 immunostaining. Similarly, the activated astrocytes and tau deposits seemed to both describe a bilayer distribution for both mutations. Interestingly, a positive correlation between ${ }^{3} \mathrm{H}$-deprenyl and ${ }^{3} \mathrm{H}$-THK5117 binding was only observed in the two ABPParc and the control brains, while there was no significant correlation in either the PSENIDE9 or the sAD brains. These observations suggest that it might be a closer relationship between activated astrocytes and tau deposits in ABPParc brains than in PSEN1DE9 brains. Since some off-target binding to monoamine oxidase B (MAO-B) has been reported for the first generation tau tracer, THK5117, we also included MK6240, a tau tracer from the second generation, with no MAO-B off-target binding [16]. No regional differences in regional binding pattern were observed between the two-tau tracers in SAD except for a difference in intensity of binding that can be due both to the difference in specific radioactivity between the two tracers as well as probably more NSP binding for THK5117. However, some differences were observed between the two-tau PET tracers since ${ }^{3} \mathrm{H}-\mathrm{MK} 6240$ showed lower binding in the PSEN1DE9 and ABPParc2 variants in comparison to ABPParcl cases and the SAD cases. This observation might suggest some difference in binding properties between these two-tau PET tracers at least in AD mutation cases. It will be interesting to study further the underlying cause of the difference between the bindings of the two-tau PET tracers in the familial form of AD. Recent Cryo-EM studies have demonstrated similar tau fibril folding structure in $\mathrm{SAD}$ and inherited $\mathrm{AD}$ (V717FAPP) [13] and it would be interesting to have similar studies comparing the tau folds in ABPParc and PSENIDE9.

It should be born in mind that the different cutting levels in the large frozen brain sections for autoradiography and in the paraffin sections from the contralateral hemisphere used for immunostaining could have affected the comparison between the ABPParc, PSENIDE9, and SAD brains as the same regions cannot be compared directly.

The results of the binding studies in brain homogenates were in general similar to those of the autoradiography studies on large frozen sections. The homogenization process of the brain most probably let us access to more binding sites than for the autoradiography. Indeed, on the autoradiography the tracer can reach only the accessible binding site, than when the brain is homogenized binding site that where inaccessible might become accessible. During the homogenization process, conformational and structural changes most probably occur in the cotton wool plaques and the ${ }^{3} \mathrm{H}$-PIB do not have access to the similar binding sites in comparison to amyloid plaques found in sAD brains. In silico computer modeling has suggested that there may be several binding sites on the amyloid fibril [17], as also suggested by in vitro binding with various amyloid ligands [18]. In this study, we observed the highest binding of ${ }^{3} \mathrm{H}-\mathrm{PIB}$ in the caudate nucleus of the PSENIDE9 brain in comparison with ABPParc and, despite the limitation of there being only one brain examined, this observation appears to be in agreement with in vitro results by $\mathrm{Ni}$ et al. [19] and in vivo results by Koivunen et al. [12]. The binding pattern for amyloid deposition is confirmed by binding assay as well as autoradiography and immunostaining. Binding of ${ }^{3} \mathrm{H}$-THK5117 and ${ }^{3} \mathrm{H}$-deprenyl in the entorhinal cortex of the ABPParc 2 brain was much higher than that in the ABPParcl brain and the SAD brain. When the results from the in vivo and in vitro studies were compared in $A \beta P P a r c 1$, we observed a trend toward a negative association between ${ }^{18} \mathrm{~F}$-FDG and ${ }^{3} \mathrm{H}$-THK5117 binding; no statistical analysis could be performed due to few data points. The time differences between in vivo/in vitro measurements might add some limitations. Increased tau deposits (as observed with ${ }^{3} \mathrm{H}$-THK5117) seemed to occur in regions with lower ${ }^{18} \mathrm{~F}-\mathrm{FDG}$ PET data, implying lower cerebral metabolism and neuronal dysfunction.

There were several differences in amyloid plaque, tau deposition and activated astrocyte between the ABPParc and PSENIDE9 brains as well as in comparison with the SAD brains. A positive association was observed between activated astrocyte and tau loads for the ABPParc brains but no such correlation was observed, respectively, neither the PSENIDE9 nor the sAD brains. Although both mutations present abnormal plaque shapes (a ring shape for ABPParc and 'cotton wool' for PSEN1DE9), these mutations in the $A P P$ and PSEN1 genes, respectively, lead to major differences in the amyloid-beta composition and also in the tau deposits and activated astrocytes hallmarks in the development of AD pathology. Finally the use of two-tau tracers showed differences in regional binding both in the PSENIDE9 but also between the two ABPParc brains suggesting difference in $\mathrm{AD}$ variants, which deserves further exploration in vivo.

\section{Data availability}

All data generated or analysed during this study are included in this published article.

Acknowledgements The authors would like to thank Pr. Hannu Kalimo and Dr. Liisa $\mathrm{T}$ Myllykangas from the Department of Pathology, University of Helsinki, Helsinki, Finland, for providing the PSEN1DE9 tissue. The authors would like to thank Pr. Bernardino Guetti and Rose Marie Richardson from the Department of Pathology \& Laboratory Medicine, Indiana University School of Medicine, and 
Indianapolis, IN, USA for provinding the sporadic AD brain tissue. The Netherlands Brain Bank is also thanked for providing the control human brains used in the binding assay.

Funding This study was financially supported by the Swedish Foundation for Strategic Research (SSF), the Swedish Research Council (project 05817, 2017-02965, 2017-06086), the Stockholm County Council-Karolinska Institutet regional agreement on medical training and clinical research (ALF grant), the Swedish Brain Foundation, the Alzheimer Foundation in Sweden, Karolinska Institutet StratNeuro, the Foundation for Old Servants, Gun and Bertil Stohne's Foundation, Gunvor och Josef Anérs stiftelsen, the Loo and Hans Osterman's Foundation, the Tore Nilsson Foundation, the KI Foundation for Geriatric Diseases, and The Swedish Dementia Association, Demensfonden, CIMED Karolinska Institutet-Stockholm County Council.

Author contributions LL, PGG, and AN designed the study. LL performed and analyzed the autoradiography and binding assay studies. LL, PGG, and NB analysed the autoradiography and draw the region of interest. NB and IN provided analyze and interpretations for immunostaining. LSA provide the images and analyze for in vivo PET. CG, MV, and MI provided the ABPParc1, PSEN1DE9, and $A \beta P P a r c 2$ case, respectively. LL, PGG, and AN, drafted the first version of the MS. All authors provided input and feedback during the process of writing the paper. All authors read and approved the final paper.

\section{Compliance with ethical standards}

Conflict of interest The authors declare that they have no conflict of interest.

Ethics approval All experiments on autopsied human brain tissue were carried out in accordance with ethical permission obtained from the regional human ethics committee in Stockholm (permission number 2011/962/31-1; 2006/901-31/3 and 2017/2301-32), Uppsala (2005/ 103, 2011/044), the medical ethics committee of the VU Medical Center for the Netherlands Brain Bank tissue (permission number 1998-06/5), Indiana University Institutional Review Board, and Helsinki University Hospital DNr 86/2014 and Valvira (National Supervisory Authority for Welfare and Health) Dnr 2855/2012.

Informed consent Informed consent was obtained for all cases investigated.

Publisher's note Springer Nature remains neutral with regard to jurisdictional claims in published maps and institutional affiliations.

Open Access This article is licensed under a Creative Commons Attribution 4.0 International License, which permits use, sharing, adaptation, distribution and reproduction in any medium or format, as long as you give appropriate credit to the original author(s) and the source, provide a link to the Creative Commons license, and indicate if changes were made. The images or other third party material in this article are included in the article's Creative Commons license, unless indicated otherwise in a credit line to the material. If material is not included in the article's Creative Commons license and your intended use is not permitted by statutory regulation or exceeds the permitted use, you will need to obtain permission directly from the copyright holder. To view a copy of this license, visit http://creativecommons. org/licenses/by/4.0/.

\section{References}

1. Basun H, Bogdanovic N, Ingelsson M, Almkvist O, Naslund J, Axelman K, et al. Clinical and neuropathological features of the arctic APP gene mutation causing early-onset Alzheimer disease. Arch Neurol. 2008;65:499-505.

2. Bettens K, Sleegers K, Van Broeckhoven C. Genetic insights in Alzheimer's disease. Lancet Neurol. 2013;12:92-104.

3. Crook R, Verkkoniemi A, Perez-Tur J, Mehta N, Baker M, Houlden $\mathrm{H}$, et al. A variant of Alzheimer's disease with spastic paraparesis and unusual plaques due to deletion of exon 9 of presenilin 1. Nat Med. 1998;4:452-5.

4. Mann DM, Takeuchi A, Sato S, Cairns NJ, Lantos PL, Rossor MN, et al. Cases of Alzheimer's disease due to deletion of exon 9 of the presenilin-1 gene show an unusual but characteristic betaamyloid pathology known as 'cotton wool' plaques. Neuropathol Appl Neurobiol. 2001;27:189-96.

5. Kalimo H, Lalowski M, Bogdanovic N, Philipson O, Bird TD, Nochlin D, et al. The Arctic AbetaPP mutation leads to Alzheimer's disease pathology with highly variable topographic deposition of differentially truncated Abeta. Acta Neuropathol Commun. 2013;1:60.

6. Scholl M, Wall A, Thordardottir S, Ferreira D, Bogdanovic N, Langstrom B, et al. Low PiB PET retention in presence of pathologic CSF biomarkers in Arctic APP mutation carriers. Neurology. 2012;79:229-36.

7. Dahlgren KN, Manelli AM, Stine WB Jr., Baker LK, Krafft GA, LaDu MJ. Oligomeric and fibrillar species of amyloid-beta peptides differentially affect neuronal viability. J Biol Chem. 2002;277:32046-53.

8. Nilsberth C, Westlind-Danielsson A, Eckman CB, Condron MM, Axelman K, Forsell C, et al. The 'Arctic' APP mutation (E693G) causes Alzheimer's disease by enhanced Abeta protofibril formation. Nat Neurosci. 2001;4:887-93.

9. Philipson O, Lord A, Lalowski M, Soliymani R, Baumann M, Thyberg J, et al. The Arctic amyloid-beta precursor protein (AbetaPP) mutation results in distinct plaques and accumulation of N- and C-truncated Abeta. Neurobiol Aging. 2012;33:1010. e1-13.

10. Thordardottir S, Kinhult Stahlbom A, Almkvist O, Thonberg H, Eriksdotter M, Zetterberg $\mathrm{H}$, et al. The effects of different familial Alzheimer's disease mutations on APP processing in vivo. Alzheimers Res Ther. 2017;9:9.

11. Thordardottir S, Stahlbom AK, Ferreira D, Almkvist O, Westman E, Zetterberg $\mathrm{H}$, et al. Preclinical cerebrospinal fluid and volumetric magnetic resonance imaging biomarkers in Swedish familial Alzheimer's disease. J Alzheimers Dis. 2015;43:1393-402.

12. Koivunen J, Verkkoniemi A, Aalto S, Paetau A, Ahonen JP, Viitanen M, et al. PET amyloid ligand [11C]PIB uptake shows predominantly striatal increase in variant Alzheimer's disease. Brain. 2008;131:1845-53.

13. Falcon B, Zhang W, Schweighauser M, Murzin AG, Vidal R, Garringer HJ, et al. Tau filaments from multiple cases of sporadic and inherited Alzheimer's disease adopt a common fold. Acta Neuropathol. 2018;136:699-708.

14. Verkkoniemi A, Kalimo H, Paetau A, Somer M, Iwatsubo T, Hardy J, et al. Variant Alzheimer disease with spastic paraparesis: neuropathological phenotype. J Neuropathol Exp Neurol. 2001;60:483-92.

15. Lemoine L, Saint-Aubert L, Nennesmo I, Gillberg PG, Nordberg A. Cortical laminar tau deposits and activated astrocytes in Alzheimer's disease visualised by (3)H-THK5117 and (3)H-deprenyl autoradiography. Sci Rep. 2017;7:45496. 
16. Leuzy A, Chiotis K, Lemoine L, Gillberg PG, Almkvist O, Rodriguez-Vieitez E, et al. Tau PET imaging in neurodegenerative tauopathies-still a challenge. Mol Psychiatry. 2019;24:1112-34.

17. Murugan NA, Halldin C, Nordberg A, Langstrom B, Agren H. The culprit is in the cave: the core sites explain the binding profiles of amyloid-specific tracers. J Phys Chem Lett. 2016;7:3313-21.
18. Ni R, Gillberg PG, Bergfors A, Marutle A, Nordberg A. Amyloid tracers detect multiple binding sites in Alzheimer's disease brain tissue. Brain. 2013;136:2217-27.

19. Ni R, Gillberg PG, Bogdanovic N, Viitanen M, Myllykangas L, Nennesmo I, et al. Amyloid tracers binding sites in autosomal dominant and sporadic Alzheimer's disease. Alzheimers Dement. 2017;13:419-30. 